\title{
Efficacy of salmeterol and formoterol combination treatment in mice with chronic obstructive pulmonary disease
}

\author{
ZHIYUAN WANG, CHUNYAN WANG and XIAOLI YANG \\ Department of Lung Disease, Yucheng City People's Hospital, Dezhou, Shangdong 350076, P.R. China \\ Received April 8, 2016; Accepted March 23, 2017
}

DOI: $10.3892 /$ etm.2017.5562

\begin{abstract}
Chronic obstructive pulmonary disease (COPD) is a severe lung disease characterized by progressive airflow limitation. Salmeterol and formoterol are two commonly used drugs in COPD therapy, which act as $\beta 2$-receptor agonists. In the current study, a mouse model of COPD induced by airway lipopolysaccharide inhalation was established. The therapeutic efficacy of salmeterol and formoterol co-treatment was investigated in this model over a 56-day-long observation period. It was also identified that functional residual capacity and inspiratory resistance were significantly improved after salmeterol and/or formoterol treatment compared with the control group (all $\mathrm{P}<0.01$ ). Furthermore, histological staining of lung tissue samples indicated that inflammation, thickening of the smooth muscle, goblet cell hyperplasia and pulmonary small vessel obstruction were reduced in the mice treated with salmeterol and/or formoterol, suggesting that salmeterol and formoterol were beneficial for ongoing airway and blood vessel remodeling in mice with COPD. The most common treatment-associated adverse events were hypertension and proteinuria. In conclusion, combined salmeterol and formoterol treatment was more effective compared with either single agent, suggesting that salmeterol and formoterol combined treatment has therapeutic value for the clinical treatment of patients with COPD.
\end{abstract}

\section{Introduction}

Chronic obstructive pulmonary disease (COPD), also known as obstructive emphysema, is caused by the narrowing of airways and lung damage $(1,2)$. In recent years, the incidence of COPD has increased markedly due to air pollution, smoking and chronic bronchitis (3). The symptoms of COPD cause a large global burden of disease $(1,4)$. COPD also has a notable impact on the quality of life of patients, frequently leading to the

Correspondence to: Professor Xiaoli Yang, Department of Lung Disease, Yucheng City People's Hospital, 127 Nanyang Road, Dezhou, Shangdong 350076, P.R. China

E-mail: yangxiaolidoctor@163.com

Key words: chronic obstructive pulmonary disease, salmeterol, formoterol impairment of activity, an increased risk of hospitalization and increased numerous symptoms including chronic bronchitis and emphysema $(5,6)$. In addition, a previous study reported that $\sim 80 \%$ of patients with COPD still exhibit deterioration of pulmonary function in a 3-year clinical investigation (7). Although the patients received different treatments, normal pulmonary function deteriorated heterogeneously (7).

Salmeterol and formoterol are two commonly used drugs in COPD therapy, which act as $\beta 2$-receptor agonists (8). Salmeterol and formoterol were identified as $\beta 2$-receptor agonists that inhibit early and late phase antigen-induced airway hyper-responsiveness $(9,10)$. Previous reports indicate that the combination of inhaled salmeterol and formoterol is a commonly used treatment protocol for patients with COPD $(11,12)$. In addition, Frampton (13) have reported that the combined use of inhaled formoterol and the corticosteroid mometasone significantly improved the lung function in patients with asthma. Furthermore, Yip et al (14) evaluated the effect of changing from fluticasone/salmeterol to mometasone/formoterol treatment in patients with COPD and identified that patients experienced COPD exacerbation after this conversion. However, the underlying mechanism of the effect of combined salmeterol and formoterol treatment in COPD is not well understood, and few reports have evaluated its efficacy in preclinical and clinical trials.

In the current study, the therapeutic efficacy of salmeterol and formoterol was evaluated in mice with COPD induced by airway lipopolysaccharide (LPS) inhalation. The therapeutic efficacy and side effects of this treatment were evaluated in a 56-day-long observation. Although salmeterol/formoterol is not currently approved for COPD therapy by the US Food and Drug Administration, evidences from clinical trials of mometasone/formoterol and salmeterol/formoterol have indicated that salmeterol/formoterol treatment is well tolerated and could improve lung function in patients with $\operatorname{COPD}(15,16)$. Based on previous clinical data $(9)$, a combined salmeterol/formoterol therapeutic approach was designed to treat mice with COPD.

\section{Materials and methods}

Ethics statement. The present study was approved by the Ethics Committee of Yucheng City People's Hospital (Dezhou, China; Approval number: YCCPH: 20130567LPX1) and performed in accordance with the recommendations of the 
Guide for the Care and Use of Laboratory Animals of Yucheng City People's Hospital. All surgery and euthanasia procedures were performed under intraperitoneal injection of sodium pentobarbital anesthesia $(50 \mathrm{mg} / \mathrm{kg})$, and all efforts were made to minimize suffering.

Cell culture. MRC-5 normal lung fibroblast cells were obtained from the American Type Culture Collection (Manassas, VA, USA). The cells were cultured in Dulbecco's modified Eagle's medium supplemented with $10 \%$ heat-inactivated fetal bovine serum (Lonza Group, Inc., Walkersville, MD, USA), 3 mM L-glutamine, $50 \mu \mathrm{g} / \mathrm{ml}$ gentamicin and $1 \%$ penicillin/streptomycin. All cells were cultured at $37^{\circ} \mathrm{C}$ and in $5 \% \mathrm{CO}_{2} . \mathrm{MRC}-5$ cell models of COPD were established through $48 \mathrm{~h}$ incubation of LPS (2.5 mg/kg, Sigma-Aldrich; Merck KGaA, Darmstadt, Germany). The MRC-5 cells (MOCK), and LPS-induced MRC-5 cells were treated with PBS (Control), salmeterol $(0.16 \mathrm{mg} / \mathrm{ml}) \mathrm{and} /$ or formoterol $(0.32 \mathrm{mg} / \mathrm{ml})$ for $24 \mathrm{~h}$ at $37^{\circ} \mathrm{C}$ for further analysis.

Reverse transcription-quantitative polymerase chain reaction (RT-qPCR) analysis. Total RNA was extracted from MRC-5 lung cells after treatment with salmeterol and/or formoterol using an RNeasy Mini kit (Qiagen Sciences, Inc., Gaithersburg, MD, USA) according to the manufacturer's protocol. Total RNA $(1 \mu \mathrm{g})$ was reverse transcribed into cDNA using a QuantiTect Reverse Transcription kit (Cat no. 205310; Qiagen Sciences, Inc.) according to the manufacturer's protocol. The cDNA (10 ng) was subjected to qPCR using SYBR Green Master mix (Bio-Rad Laboratories, Inc., Hercules, CA, USA). The reaction conditions were performed as follows: $95^{\circ} \mathrm{C}$ for $10 \mathrm{~min}$ and 35 cycles of $95^{\circ} \mathrm{C}$ for $20 \mathrm{sec}$ and $58^{\circ} \mathrm{C}$ for $1 \mathrm{~min}$. Relative mRNA expression changes were calculated using the $2^{-\triangle \Delta C q}$ method (17). The results are expressed as a fold of the control. All primers were synthesized by Invitrogen; Thermo Fisher Scientific, Inc. and are presented in Table I.

Evaluation of toxicity. Toxicity was graded using the National Cancer Institute Common Toxicity Criteria (CTC; version 3.0) (18). Mice received $0.08,0.16,0.32$ or $0.40 \mathrm{mg}$ salmeterol or formoterol once a day for a total of 10 days $(n=5$ in each group). Hypertension, diarrhea, proteinuria, vomiting, lethargy, rash, fatigue, constipation, weight, appetite, epistaxis, hypertriglyceridemia and peripheral edema were evaluated and recorded every 2 days during therapy. A dose-limiting toxicity (DLT) was defined as any of the drug-associated toxicities described previously (19).

Animal experiments. A total of 80 male C57BL/6 mice (6-8 weeks old, body weight: 32-35 g) were purchased from the West China Experimental Animal Center of Sichuan University (Sichuan, China). All mice were maintained at $22-25^{\circ} \mathrm{C}$ and relative humidity of $50 \pm 5 \%$ in a 12 -h light/dark cycle with ad libitum access to food and water. Mice were used to establish a COPD model as described previously (20) and divided into five groups (Mock, Mock, salmeterol, formoterol and co-treatment of salmeterol and formoterol; n=16/group). Each mouse in the treatment groups received salmeterol $(0.16 \mathrm{mg} / \mathrm{kg})$ and $/$ or formoterol $(0.32 \mathrm{mg} / \mathrm{kg})$ at the maximum tolerated dose (MTD) with PBS treatment used as the control.
Experimental mice were administered with drugs once daily for a total of 56 days. The therapeutic effects of salmeterol and/or formoterol on mice with COPD were measured as described previously (21).

Pulmonary function test. The pulmonary function of the mice after treatment with salmeterol and/or formoterol was assessed by recording changes in airway resistance and functional residual capacity using a Buxco Pulmonary Mechanics system (Buxco Electronics, Inc., Wilmington, NC, USA) according to the manufacturer's protocol. The efficacy of salmeterol and/or formoterol on mice with COPD was analyzed by COPD assessment test scores (22). The severity is determined based on score: low, $<4$, medium, $\geq 4$ and $<9$ and high, $\geq 9$.

Histopathology. Hypertrophy and hyperplasia of the goblet cells on airway surfaces, inflammatory cell infiltration, alveolar structural changes, and airway smooth muscle and intima cells were examined in the lungs of experimental mice by histopathology. On day 28 , lung tissue samples were removed from the central airway, as previously described (23), then sectioned, fixed with $4 \%$ paraformaldehyde at $4^{\circ} \mathrm{C}$ for $12 \mathrm{~h}$. Lung tissues were embedded in paraffin and cut into $4 \mu \mathrm{m}$ thick sections for hematoxylin and eosin staining at $37^{\circ} \mathrm{C}$ for $2 \mathrm{~h}$. Lung tissue sections were also stained with masson staining for $2 \mathrm{~h}$ at $37^{\circ} \mathrm{C}$ to analyze the efficacy of salmeterol and/or formoterol, according to previous study (24).

Statistical analysis. All data are presented as the mean \pm standard error of the mean. Differences between groups were compared using an unpaired Student's t-test. Comparisons between multiple groups were performed using analysis of the one-way ANOVA variance. Analyses were performed using SPSS 19.0 (IBM Corp., Armonk, NY, USA) and GraphPad Prism 5 software (version 5.0; GraphPad Software, Inc., La Jolla, CA, USA). ${ }^{*} \mathrm{P}<0.05$ and ${ }^{* *} \mathrm{P}<0.01$ was considered to indicate a statistically significant difference.

\section{Results}

Duration of treatment and MTD of salmeterol and for moterol. All mice salmeterol and/or formoterol (n=16/group). The median overall duration of treatment for the mice was 10 days for this analysis. Mice received $0.08,0.16,0.32$ or $0.40 \mathrm{mg}$ of salmeterol or formoterol. A dose of $0.16 \mathrm{mg}$ salmeterol and $0.32 \mathrm{mg}$ formoterol once daily were identified as the MTD (Table II) as previously described (25). The most common CTC grade $\geq 3$ treatment-associated adverse events at these dosages were proteinuria and hypertension ( $\geq 15 \%$ each; Table III).

Efficacy of salmeterol and formoterol treatment in vitro. After confirming the MTD, biological markers of COPD were used to evaluate the efficacy of salmeterol and/or formoterol in the LPS-induced MRC-5 cells. Krebs von den Lungen-6 (KL-6), C-C motif chemokine ligand 18 (CCL-18), matrix metalloproteinase-7 (MMP-7) and surfactant protein A (SP-A) mRNA expression levels were analyzed in LPS-induced MRC-5 cells The results indicated that KL-6, CCL-18 and MMP-7 mRNA expression levels were significantly higher in LPS-induced 
Table I. Primer sequences of used for reverse transcription-quantitative polymerase chain reaction.

\begin{tabular}{lll}
\hline Gene & \multicolumn{1}{c}{ Forward primer $\left(5^{\prime}-3^{\prime}\right)$} & \multicolumn{1}{c}{ Reverse primer $\left(5^{\prime}-3^{\prime}\right)$} \\
\hline KL-6 & ATTTGTCTGGCTGGAAAGGCAACC & AAGCACTGAAAGACGCTGCTTTGG \\
CCL-18 & AAGACCTTCTGCCACTGGGAACAT & AGTTGCCATCTCCTGTGTGATCCT \\
MMP-7 & TGCCCACCGTCCTTTCTTGTT & GCTGACTTGACTCATGGCT \\
SP-A & TCTGACGAATCTCCTCCAC & AAAGTTTCAATGACCAAGC \\
TNF- $\alpha$ & TCCAGACTTCCTTGAGACA & GGCGATTACAGACACAACT \\
IL-1 & GGCTGCTTCCAAACCTTTGA & GAAGACACGGATTCCATGGT \\
IL-18 & ACACCTGTCTCGCAGACCAC & TCAGCTGCTCCAGCACCAA \\
TGF- $\beta$ & ATCCATGTGTGACCATGAGGAAATG & TCGGCTAGTTAGGGTACACTTC \\
IL-4 & GTGAGGAACAAGCCAGAG $\gamma$ & TGACCAGAAGAAGGAATGC \\
$\beta-$ actin & CACCCTCTGTCACCTGCTCAA & ATGGCGCTGAGAAGACTTGGT \\
\hline
\end{tabular}

KL-6, Krebs von den Lungen-6; CCL-18, C-C motif chemokine ligand 18; MMP-7, matrix metalloproteinase-7; SP-A, surfactant protein A; TNF- $\alpha$, tumor necrosis factor $\alpha$; IL, interleukin; TGF- $\beta$, transforming growth factor $\beta$; IFN- $\gamma$, interferon $\gamma$.

Table II. Treatment-related adverse event with an overall incidence $\geq 10 \%$.

Number of adverse events

\begin{tabular}{|c|c|c|c|c|c|c|c|c|c|}
\hline \multicolumn{4}{|c|}{ Salmeterol, mg (n=16/group) } & \multirow[b]{2}{*}{ Total } & \multicolumn{4}{|c|}{ Formoterol, mg (n=16/group) } & \multirow[b]{2}{*}{ Total } \\
\hline 0.08 & 0.16 & 0.32 & 0.40 & & 0.08 & 0.16 & 0.32 & 0.40 & \\
\hline 2 & 3 & 3 & 4 & 12 & 2 & 2 & 4 & 5 & 13 \\
\hline 0 & 1 & 1 & 1 & 3 & 0 & 1 & 1 & 2 & 4 \\
\hline 2 & 3 & 4 & 5 & 14 & 2 & 4 & 4 & 5 & 15 \\
\hline 1 & 0 & 1 & 2 & 4 & 1 & 1 & 1 & 1 & 4 \\
\hline 0 & 0 & 1 & 1 & 2 & 0 & 0 & 1 & 2 & 3 \\
\hline 0 & 1 & 1 & 1 & 3 & 1 & 1 & 1 & 2 & 5 \\
\hline 1 & 1 & 1 & 2 & 5 & 1 & 1 & 2 & 2 & 6 \\
\hline 1 & 1 & 2 & 2 & 6 & 1 & 1 & 1 & 2 & 5 \\
\hline 3 & 2 & 3 & 3 & 11 & 1 & 2 & 3 & 4 & 10 \\
\hline 1 & 1 & 2 & 3 & 7 & 1 & 1 & 2 & 4 & 8 \\
\hline 2 & 1 & 2 & 3 & 8 & 2 & 1 & 2 & 4 & 9 \\
\hline 1 & 1 & 1 & 2 & 5 & 0 & 1 & 1 & 2 & 4 \\
\hline 1 & 1 & 2 & 3 & 7 & 1 & 1 & 2 & 2 & 6 \\
\hline 15 & 16 & 24 & 32 & 87 & 13 & 17 & 25 & 37 & 92 \\
\hline
\end{tabular}

MRC-5 control cells compared with the non-LPS-induced mock group, while salmeterol and/or formoterol significantly inhibited KL-6, CCL-18 and MMP-7 expression compared with the control group (all $\mathrm{P}<0.01$; Fig. $1 \mathrm{~A}-\mathrm{C}$ ). In addition, the data demonstrated that combination treatment with salmeterol and formoterol significantly reduced the expression of KL-6, CCL-18 MMP-7 compared with either single treatment $(\mathrm{P}<0.01$; Fig. 1A-C). Furthermore, the results indicated that SP-A expression was significantly lower in LPS-induced MRC-5 control cells compared with the non-induced mock group, while salmeterol and/or formoterol significantly increased SP-A expression (all P<0.01; Fig. 1D). Salmeterol and formoterol combination treatment significantly increased the expression of SP-A compared with either single treatment $(\mathrm{P}<0.01$; Fig. 1D). These data indicate that salmeterol, formoterol and, particularly, combined salmeterol/formoterol treatment efficiently reduces the symptoms of COPD.

Efficacy of salmeterol and formoterol in vivo. The therapeutic effects of salmeterol and/or formoterol treatment on mice with COPD were evaluated in the present study. The results indicated that the body weight of the control mice decreased over the study period, while treatment with salmeterol, formoterol or a combination of the two significantly inhibited this weight loss (all $\mathrm{P}<0.01$; Fig. 2A). In addition, COPD assessment test scores were markedly improved by 
Table III. Treatment-related hypertension and proteinuria by Common Toxicity Criteria grade.

Number of adverse events

\begin{tabular}{cccc}
\cline { 2 - 4 } Adverse event & Salmeterol $0.16 \mathrm{mg}(\mathrm{n}=14)$ & Formoterol $0.32 \mathrm{mg}(\mathrm{n}=14)$ & Total \\
\hline Hypertension & 3 & 3 & 6 \\
Grade 1 & 1 & 1 & 2 \\
Grade 2 & 2 & 1 & 3 \\
Grade 3 & 0 & 1 & 1 \\
Proteinuria & 5 & 6 & 11 \\
Grade 1 & 1 & 1 & 2 \\
Grade 2 & 2 & 3 & 5 \\
Grade 3 & 2 & 2 & 4 \\
\hline
\end{tabular}

A

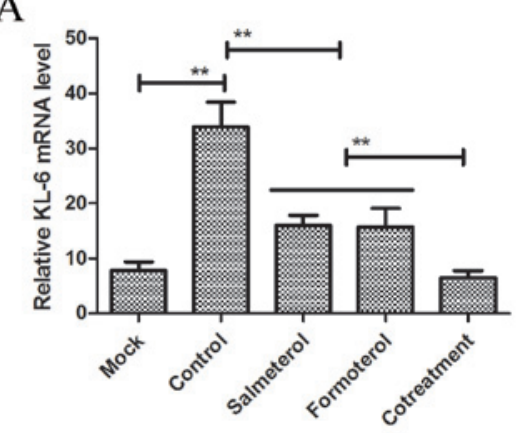

C

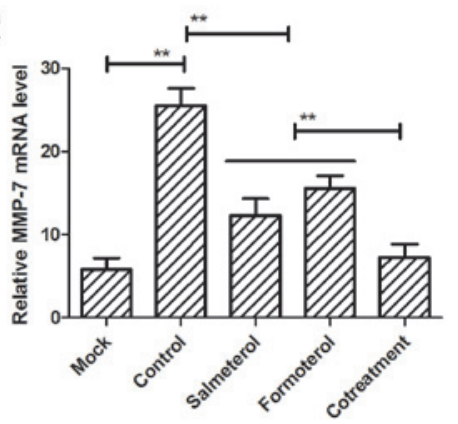

$\mathrm{B}$

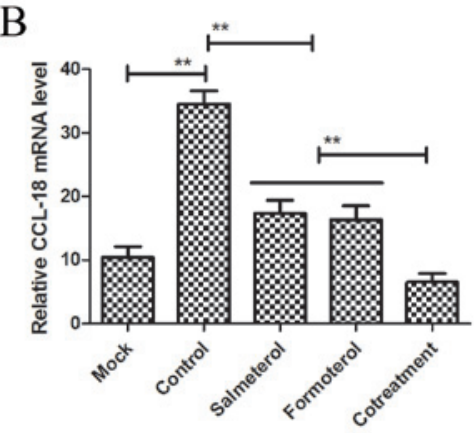

$\mathrm{D}$

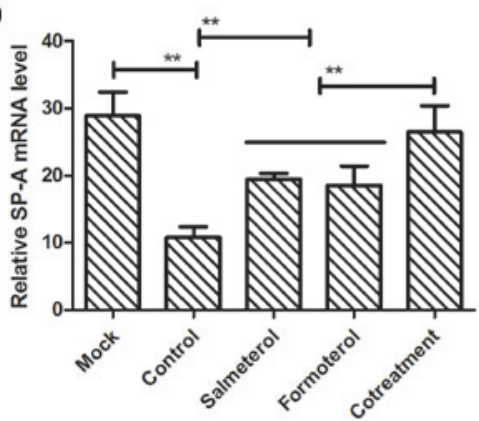

Figure 1. Expression of biological markers of chronic obstructive pulmonary disease in experimental mice. (A) KL-6, (B) CCL-18, (C) MMP-7 and (D) SP-A mRNA expression levels were analyzed in mice treated with salmeterol and/or formoterol. " $\mathrm{P}<0.01$ vs. the control group. KL-6, Krebs von den Lungen-6; CCL-18, C-C motif chemokine ligand 18; MMP-7, matrix metalloproteinase-7; SP-A, surfactant protein A.

salmeterol and/or formoterol in mice with COPD (Fig. 2B). Furthermore, the functional residual capacity and inspiratory resistance data were evaluated. As presented in Fig. 2C, the functional residual capacity was $0.382 \pm 0.052,0.410 \pm 0.038$ and $0.442 \pm 0.058 \mathrm{ml}$ in the salmeterol, formoterol and combined treatment groups, respectively, which was significantly higher compared with that of the control group $(0.210 \pm 0.022 \mathrm{ml} ; \mathrm{P}<0.01)$. As illustrated in Fig. 2D, the inspiratory resistance was $0.728 \pm 0.032,0.744 \pm 0.042$ and $0.652 \pm 0.058 \mathrm{~cm} \mathrm{H} \mathrm{H}_{2} \mathrm{O} / \mathrm{ml} / \mathrm{sec}$ in the salmeterol, formoterol and combination treatment groups, respectively, which was significantly lower compared with that of the control group (1.078 $\left.\pm 0.062 \mathrm{~cm} \mathrm{H} \mathrm{H}_{2} \mathrm{O} / \mathrm{ml} / \mathrm{sec} ; \mathrm{P}<0.01\right)$. These data suggest that salmeterol, formoterol and combined treatment have therapeutic effects in mice with COPD.
Levels of inflammatory factors in mice with COPD. COPD is associated with the increased production of inflammatory factors and is characterized by a progressive worsening of airflow (26). Therefore, in the current study, the mRNA levels of the inflammatory factors interleukin (IL)-1, tumor necrosis factor (TNF)- $\alpha$, interferon (IFN)- $\gamma$, transforming growth factor (TGF)- $\beta$, IL-18 and IL-4 were evaluated in the lung cells of mice with COPD after salmeterol and/or formoterol treatment using RT-qPCR. As illustrated in Fig. 3A-C, the results demonstrated that IFN- $\gamma$, IL-18 and IL-4 expression levels were significantly downregulated after salmeterol and/or formoterol treatment compared with the control group (all $\mathrm{P}<0.01$ ). In addition, co-treatment with salmeterol and formoterol significantly reduced IFN- $\gamma$, IL-18 and IL-4 expression compared with single salmeterol or formoterol 

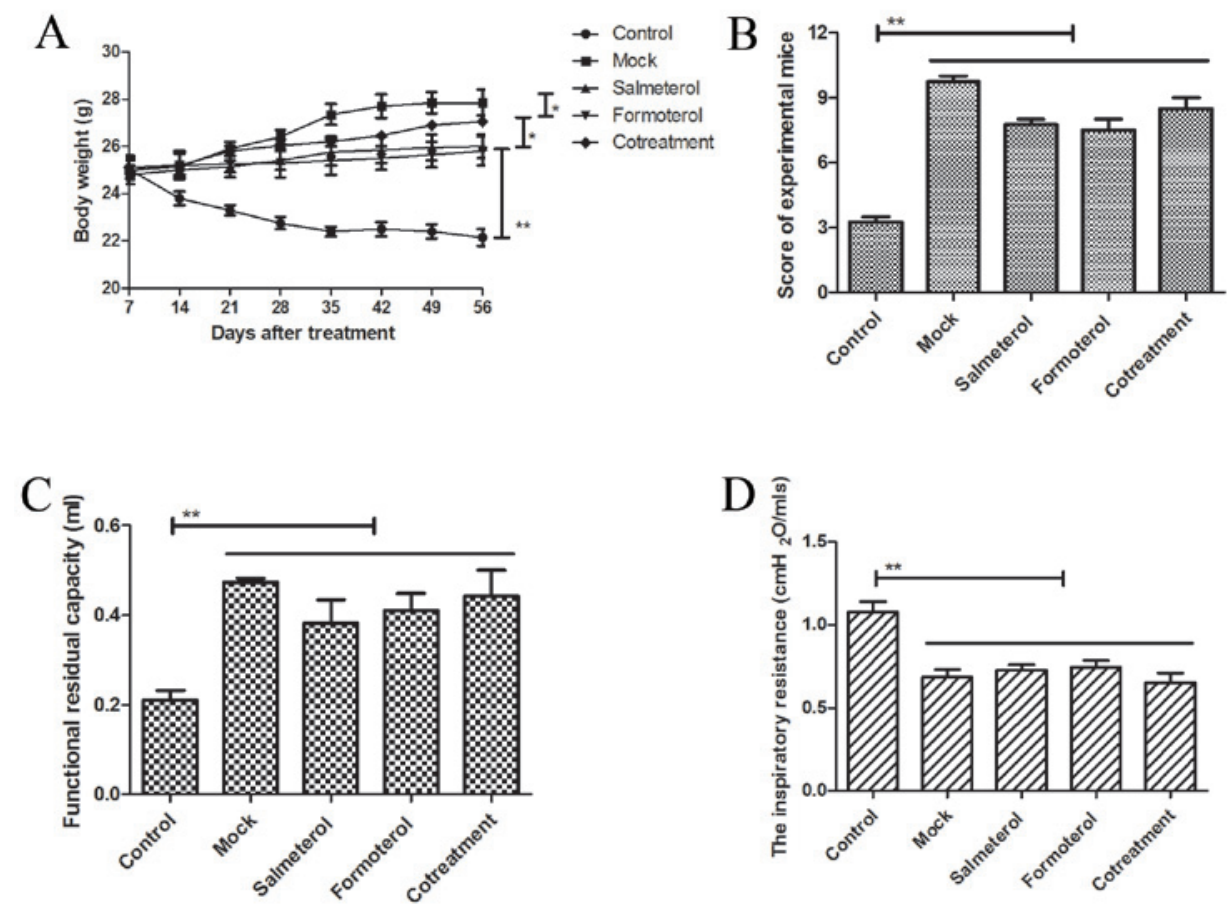

Figure 2. Therapeutic effects of salmeterol and/or formoterol on mice with COPD. (A) Body weight of mice with COPD during treatment. (B) COPD assessment test scores of experimental mice treated with salmeterol and/or formoterol. (C) Functional residual capacity in mice with COPD after salmeterol and/or formoterol treatment. (D) Inspiratory resistance in mice with COPD after salmeterol and/or formoterol treatment. ${ }^{* *} \mathrm{P}<0.01$ vs. the control group. COPD, chronic obstructive pulmonary disease.

A

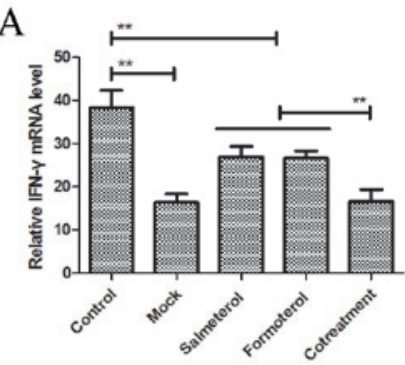

$\mathrm{D}$

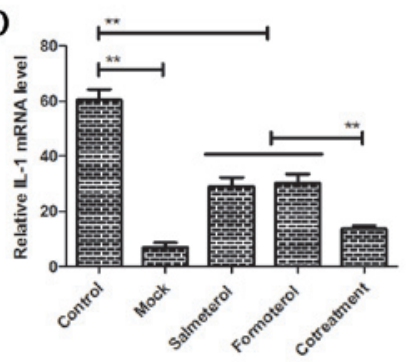

B

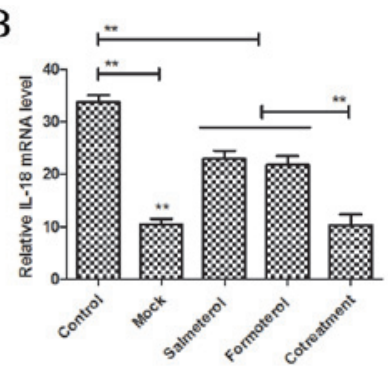

E

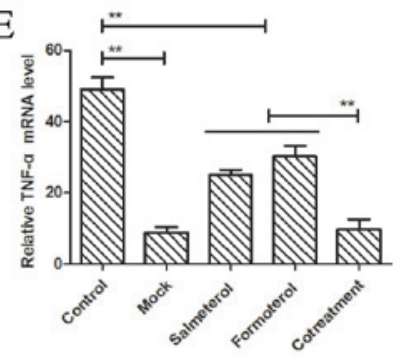

$\mathrm{C}$

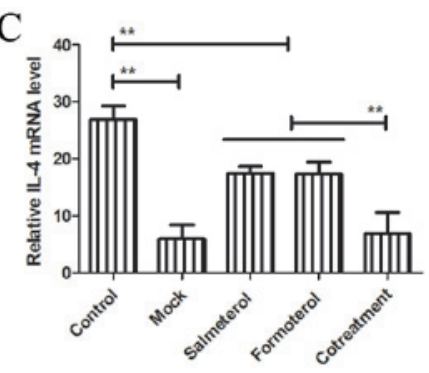

$\mathrm{F}$

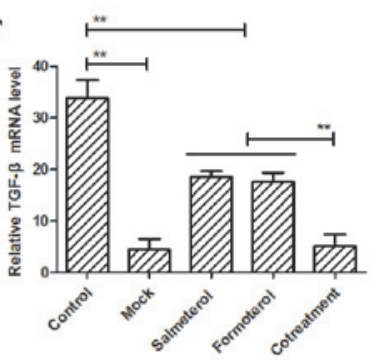

Figure 3. Expression of inflammatory factors in mice with COPD after salmeterol and/or formoterol treatment. (A) IFN- $\gamma$, (B) IL-18, (C) IL-4, (D) IL-1, (E) TNF- $\alpha$ and (F) TGF- $\beta$ mRNA expression in the lung cells of mice with COPD treated with salmeterol and/or formoterol. ${ }^{* *} \mathrm{P}<0.01$ vs. the control group. COPD, chronic obstructive pulmonary disease; IFN- $\gamma$, interferon $\gamma$; IL, interleukin; TNF- $\alpha$, tumor necrosis factor $\alpha$; TGF- $\beta$, transforming growth factor $\beta$.

treatment (all $\mathrm{P}<0.01$; Fig. 3A-C). As presented in Fig. 3D-F, IL-1, TNF- $\alpha$ and TGF- $\beta$ expression levels were significantly downregulated after salmeterol and/or formoterol treatment compared with the control group (all $\mathrm{P}<0.01$ ). However, co-treatment with salmeterol and formoterol significantly reduced IL-1, TNF- $\alpha$ and TGF- $\beta$ expression compared with either single treatment (all $\mathrm{P}<0.01$; Fig. 3D-F). These results suggest that inflammatory factors were decreased after salmeterol and/or formoterol treatment.

Pathological analysis of the efficacy of salmeterol and formoterol treatment in mice with COPD. The pathological features and long-term effects of salmeterol and formoterol treatment were evaluated in mice with COPD. 

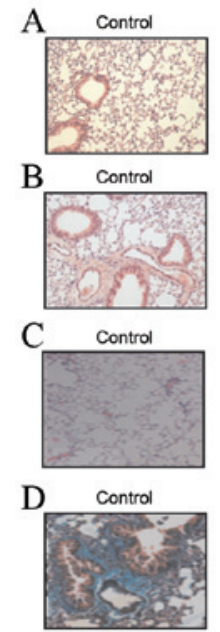

E Control
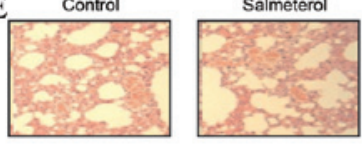

Salmeterol

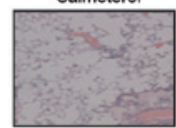

Salmeterol
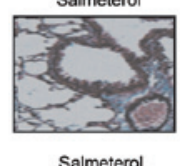

Figure 4. Histopathological assessment of lung tissue samples from mice with chronic obstructive pulmonary disease after salmeterol and/or formoterol treatment. Representative images of (A) hypertrophy and hyperplasia of goblet cells on airway surface, (B) alveolar structure, (C) airway smooth muscle, (D) smooth muscle cells in the small arteries and (E) inflammatory cell infiltration and smooth muscle cells. Magnification, x40.

As demonstrated in Fig. 4A, hypertrophy and hyperplasia of goblet cells on the airway surface was inhibited in salmeterol and/or formoterol-treated mice compared with the control group. Salmeterol and/or formoterol treatment also contributed to repair of alveolar structure (Fig. 4B). In addition, Masson staining indicated that airway smooth muscle was thinned and collagen deposition was decreased in the lungs of salmeterol and/or formoterol-treated mice compared with the control group, suggesting that these treatments aid in airway repair (Fig. 4C). It was also observed that intima cells presented typical morphology and smooth muscle cells were arranged more regularly in the small arteries of salmeterol and/or formoterol-treated mice compared with the control group (Fig. 4D). The present study demonstrated that inflammatory cell infiltration and smooth muscle cell thickening was reduced in salmeterol and/or formoterol-treated mice compared with the control group (Fig. 4E). It was observed that co-treatment markedly improved pathological features of COPD compared with salmeterol, formoterol and control groups. These results indicate that combined salmeterol and formoterol treatment is more efficient for the treatment of COPD.

\section{Discussion}

The results of the present study indicate that combined salmeterol and formoterol treatment exhibits therapeutic efficacy for mice with COPD induced by LPS. The present study revealed that beneficial inflammatory factors in the lung cells were increased in mice treated with salmeterol and formoterol. Among these inflammatory factors, IFN- $\gamma$, IL-18 and IL-4 expression levels were downregulated and IL-1, TNF- $\alpha$ and TGF- $\beta$ expression levels were upregulated after salmeterol and/or formoterol treatment. The results of the current study also demonstrated that no inflammatory cell infiltration or smooth muscle cell thickening was observed in salmeterol and formoterol-treated mice with COPD. Hypertrophy and hyperplasia of goblet cells on the airway surface was inhibited in salmeterol and/or formoterol-treated mice with COPD compared with the control group. In addition, airway smooth muscle was thinned, collagen deposition was decreased, intima cells exhibited typical morphology and smooth muscle cells were arranged more regularly in the small arteries of the lungs after salmeterol and formoterol treatment. Collectively, these data suggest that salmeterol and formoterol inhibit inflammation and reduce the histopathological characteristics of COPD.

Currently, chronic lung diseases, including asthma and COPD, are a global medical treatment burden and this burden is increasing (27-32). Statistics indicate that COPD is a major cause of morbidity and mortality worldwide (33). The World Health Organization has predicted that COPD will become the third most common non-cancer cause of mortality worldwide in 2020 (34). Drug therapies for COPD suppress inflammation in the small airways and lung parenchyma (35). Salmeterol, a $\beta 2$-receptor agonist, is recommended as a long-acting bronchodilator for patients with COPD (36). Restrepo et al (8) identified that salmeterol xinafoate and fluticasone propionate treatment improved the survival rate of patients with severe COPD. In addition, Ryan et al (37) indicated that salmeterol also improved nocturnal sleeping arterial oxygen saturation and sleep quality. These reports suggest that salmeterol is an effective drug for treatment of COPD.

Formoterol is one of the most commonly used long-acting $\beta 2$-receptor agonist drugs that is licensed for use in patients with COPD (38). A previous study indicated that symptoms of COPD were relieved through the improvement of inflammation by bronchodilators, including $\beta 2$-receptor agonists and anti-muscarinic agents (39). Fixed-dose drug combinations, including vilanterol/umeclidinium, indacaterol/glycopyrronium, olodaterol/tiotropium and formoterol/aclidinium, are licensed for the treatment of COPD worldwide (39). Schunemann (40) identified that formoterol combined with tiotropium improved airflow obstruction in COPD and improved dyspnea, asthma and chest distress. These reports suggest that formoterol is an effective drug for the treatment of COPD.

Previous studies have reported that comprehensive pharmacological treatments have improved the overall survival of patients with COPD $(16,41-43)$. In the current study, the efficacy of a fixed-dose combination of formoterol and salmeterol was evaluated in a mouse model of COPD. The experimental data suggested that this fixed-dose combination of formoterol and salmeterol decreased levels of proinflammatory factors, and was more effective compared with either single treatment. Notably, it was observed that a fixed-dose combination of formoterol and salmeterol contributed to the repair of alveolar structure and a reduction of COPD symptoms compared with either single treatment or the control group.

In conclusion, repeated treatment with a fixed-dose combination of formoterol and salmeterol by inhalation led to an improvement in the symptoms and characteristics of COPD in the present study. This suggests that that co-treatment with salmeterol and formoterol may be an effective approach for COPD therapy. 


\section{References}

1. Brusasco V and Pellegrino R: Spirometry in chronic obstructive pulmonary disease. From rule of thumb to science. Am J Respir Crit Care Med 193: 704-706, 2016.

2. Lim HJ, Weinheimer O, Wielputz MO, Dinkel J, Hielscher T, Gompelmann D, Kauczor HU and Heussel CP: Fully automated pulmonary lobar segmentation: Influence of different prototype software programs onto quantitative evaluation of chronic obstructive lung disease. PLoS One 11: e0151498, 2016.

3. Aksenova IZ and Burduli NM: Pathogenetic effects of low-intensity laser therapy for chronic obstructive pulmonary disease. Ter Arkh 88: 32-35, 2016 (In Russian).

4. Grainge C, Thomas PS, Mak JC, Benton MJ, Lim TK and Ko FW: Year in review 2015: Asthma and chronic obstructive pulmonary disease. Respirology 21: 765-775, 2016.

5. Watz H: Chronic obstructive pulmonary disease: When pulmonologists do something good for the heart. Am J Respir Crit Care Med 193: 703-704, 2016.

6. Xie L, Yang F and Sun S: Expression of miR-21 in peripheral blood serum and mononuclear cells in patients with chronic obstructive pulmonary disease and its clinical significance. Zhong Nan Da Xue Xue Bao Yi Xue Ban 41: 238-243, 2016 (In Chinese).

7. Wang J, Zhou XM, Yang X, Zhao ST, Ma QL and Wang CZ: A three years longitudinal follow-up study of pulmonary function changes in patients with chronic obstructive pulmonary disease. Zhonghua Nei Ke Za Zhi 55: 302-306, 2016 (In Chinese).

8. Restrepo RD, Tate A and Coquat J: Evaluation of salmeterol xinafoate plus fluticasone propionate for the treatment of chronic obstructive pulmonary disease. Expert Opin Pharmacother 14 1993-2002, 2013.

9. Larsson K, Janson C, Lisspers K, Jørgensen L, Stratelis G, Telg G, Ställberg B and Johansson G: Combination of budesonide/formoterol more effective than fluticasone/salmeterol in preventing exacerbations in chronic obstructive pulmonary disease: The PATHOS study. J Intern Med 273: 584-594, 2013.

10. Mochizuki H, Nanjo Y and Takahashi H: Better adherence to a transdermal tulobuterol patch than inhaled salmeterol in elderly chronic obstructive pulmonary disease patients. Geriatr Gerontol Int 13: 398-404, 2013.

11. Chatterjee A, Shah M, D'Souza AO, Bechtel B, Crater G and Dalal AA: Observational study on the impact of initiating tiotropium alone versus tiotropium with fluticasone propionate/salmeterol combination therapy on outcomes and costs in chronic obstructive pulmonary disease. Respir Res 13: 15, 2012.

12. Akamatsu K, Matsunaga K, Sugiura H, Koarai A, Hirano T, Minakata $Y$ and Ichinose M: Improvement of airflow limitation by fluticasone Propionate/Salmeterol in chronic obstructive pulmonary disease: What is the Specific Marker? Front Pharmacol 2: 36,2011

13. Frampton JE: Mometasone/formoterol inhalation aerosol: In asthma uncontrolled on medium- or high-dose inhaled corticosteroids. Drugs 72: 1229-1241, 2012.

14. Yip E, Karimi S and Pien LT: Evaluation of a therapeutic interchange from Fluticasone/Salmeterol to Mometasone/Formoterol in patients with chronic obstructive pulmonary disease. J Manag Care Spec Pharm 22: 316-323, 2016.

15. Kosoglou T, Hubbell J, Xuan F, Cutler DL, Meehan AG, Kantesaria B and Wittmer BA: Comparison of the systemic bioavailability of mometasone furoate after oral inhalation from a mometasone furoate/formoterol fumarate metered-dose inhaler versus a mometasone furoate dry-powder inhaler in patients with chronic obstructive pulmonary disease. Int J Chron Obstruct Pulmon Dis 8: 107-116, 2013.

16. Rennard SI, Tashkin DP, McElhattan J, Goldman M, Ramachandran S, Martin UJ and Silkoff PE: Efficacy and tolerability of budesonide/formoterol in one hydrofluoroalkane pressurized metered-dose inhaler in patients with chronic obstructive pulmonary disease: Results from a 1-year randomized controlled clinical trial. Drugs 69: 549-565, 2009.

17. Livak KJ and Schmittgen TD: Analysis of relative gene expression data using real-time quantitative PCR and the 2(-Delta Delta C(T)) method. Methods 25: 402-408, 2001

18. Huynh-Le MP, Zhang Z, Tran PT, DeWeese TL and Song DY: Low interrater reliability in grading of rectal bleeding using National Cancer Institute Common Toxicity Criteria and Radiation Therapy Oncology Group Toxicity scales: A survey of radiation oncologists. Int J Radiat Oncol Biol Phys 90: 1076-1082, 2014.
19. Boss DS, Glen H, Beijnen JH, Keesen M, Morrison R, Tait B, Copalu W, Mazur A, Wanders J, O'Brien JP, et al: A phase I study of E7080, a multitargeted tyrosine kinase inhibitor, in patients with advanced solid tumours. Br J Cancer 106: 1598-1604, 2012.

20. Shu J, Lu W, Li D, Liang Z, Xu X, Zhang B and Wang J: Nose-only cigarette smoke exposure plus airway lipopolysaccharide inhalation induced chronic obstructive pulmonary disease and associated pulmonary hypertension in mice. Zhonghua Jie He He Hu Xi Za Zhi 38: 907-911, 2015 (In Chinese)

21. Li WL and Pauluhn J: Comparative assessment of the sensory irritation potency in mice and rats nose-only exposed to ammonia in dry and humidified atmospheres. Toxicology 276: 135-142, 2010.

22. Jones PW, Tabberer M and Chen WH: Creating scenarios of the impact of COPD and their relationship to COPD Assessment Test (CAT) scores. BMC Pulm Med 11: 42, 2011.

23. Jaques JA, Peres Rezer JF, Ruchel JB, Gutierres J, Bairros AV, Gomes Farias IL, Almeida da Luz SC, Mello Bertoncheli Cd, Chitolina Schetinger MR, Morsch VM and Leal DB: A method for isolation of rat lymphocyte-rich mononuclear cells from lung tissue useful for determination of nucleoside triphosphate diphosphohydrolase activity. Anal Biochem 410: 34-39, 2011.

24. Yu TS, Wang X, Zhang HD, Bai RF, Zhao R and Guan DW Evaluation of specific neural marker GAP-43 and TH combined with Masson-trichrome staining for forensic autopsy cases with old myocardial infarction. Int J Legal Med: Apr 11, 2017 (Epub ahead of print)

25. Paranjpe MG, Denton MD, Vidmar TJ and Elbekai RH: Regulatory forum opinion Piece*: Retrospective evaluation of doses in the 26-week Tg.rasH2 mice carcinogenicity studies: Recommendation to eliminate high doses at maximum tolerated dose (MTD) in future studies. Toxicol Pathol 43: 611-620, 2015.

26. Loza MJ, Watt R, Baribaud F, Barnathan ES and Rennard SI: Systemic inflammatory profile and response to anti-tumor necrosis factor therapy in chronic obstructive pulmonary disease. Respir Res 13: 12, 2012.

27. Agrawal A: Dendritic Cell-Airway epithelial cell Cross-Talk changes with age and contributes to chronic lung inflammatory diseases in the elderly. Int J Mol Sci 18: pii: E1206, 2017.

28. Wang Z, Zou Z, Yang Z, Dong Y and Ma J: Association between exposure to the Chinese famine during infancy and the risk of self-reported chronic lung diseases in adulthood: A cross-sectional study. BMJ Open 7: e015476, 2017.

29. Attia EF, Miller RF and Ferrand RA: Bronchiectasis and other chronic lung diseases in adolescents living with HIV. Curr Opin Infect Dis 30: 21-30, 2017.

30. Horita N, Miyazawa N, Morita S, Kojima R, Kimura N, Kaneko T and Ishigatsubo Y: Long-acting beta-agonists reduce mortality of patients with severe and very severe chronic obstructive pulmonary disease: A propensity score matching study. Respir Res 14: 62, 2013.

31. Zhou QT, Mei JJ, He B, Huang SG, Shi Y, Wen FQ and Zhao MW: Chronic obstructive pulmonary disease assessment test score correlated with dyspnea score in a large sample of Chinese patients. Chin Med J (Engl) 126: 11-15, 2013.

32. Steer J, Gibson J and Bourke SC: The DECAF Score: Predicting hospital mortality in exacerbations of chronic obstructive pulmonary disease. Thorax 67: 970-976, 2012.

33. Santus P, Radovanovic D, Paggiaro P, Papi A, Sanduzzi A, Scichilone $\mathrm{N}$ and Braido F: Why use long acting bronchodilators in chronic obstructive lung diseases? An extensive review on formoterol and salmeterol. Eur J Intern Med 26: 379-384, 2015.

34. Rosselli D, Karpf E, Olaya A, Castañeda-Cardona C, Triana JJ, Bayona JG, Lasalvia P, Restrepo P and Laserna A: Systematic review and meta-analysis of the effectiveness and safety of combination therapy with glycopirronium-indacaterol compared with other first line therapies in patients with chronic obstructive pulmonary disease. Value Health 18: A494, 2015.

35. Barnes PJ and Hansel TT: Prospects for new drugs for chronic obstructive pulmonary disease. Lancet 364: 985-996, 2004.

36. Vogelmeier CF, Bateman ED, Pallante J, Alagappan VK, D'Andrea P, Chen H and Banerji D: Efficacy and safety of once-daily QVA149 compared with twice-daily salmeterol-fluticasone in patients with chronic obstructive pulmonary disease (ILLUMINATE): A randomised, double-blind, parallel group study. Lancet Respir Med 1: 51-60, 2013. 
37. Ryan S, Doherty LS, Rock C, Nolan GM and McNicholas WT: Effects of salmeterol on sleeping oxygen saturation in chronic obstructive pulmonary disease. Respiration 79: 475-481, 2010.

38. Tashkin DP, Rennard SI, Martin P, Ramachandran S, Martin UJ, Silkoff PE and Goldman M: Efficacy and safety of budesonide and formoterol in one pressurized metered-dose inhaler in patients with moderate to very severe chronic obstructive pulmonary disease: Results of a 6-month randomized clinical trial. Drugs 68: 1975-2000, 2008.

39. Cazzola M, Rogliani $P$ and Matera MG: Aclidinium bromide/formoterol fumarate fixed-dose combination for the treatment of chronic obstructive pulmonary disease. Expert Opin Pharmacother 14: 775-781, 2013.

40. Schünemann HJ: Formoterol in addition to tiotropium improved airflow obstruction in chronic obstructive pulmonary disease. ACP J Club 145: 39, 2006.
41. Tashkin DP and Varghese ST: Combined treatment with formoterol and tiotropium is more efficacious than treatment with tiotropium alone in patients with chronic obstructive pulmonary disease, regardless of smoking status, inhaled corticosteroid use, baseline severity, or gender. Pulm Pharmacol Ther 24: 147-152, 2011.

42. Antoniu SA, Carone M and Sampablo I: Triple inhaled therapy in stable chronic obstructive pulmonary disease: The earlier, the better? Evaluation of Welte T, Miravitlles M, Hernandez P, et al. Efficacy and tolerability of budesonide/formoterol added to tiotropium in patients with chronic obstructive pulmonary disease. Am J Respir Crit Care Med 180: 741-750, 2009. Expert Opin Pharmacother 11: 1039-1042, 2010.

43. Welte T, Miravitlles M, Hernandez P, Eriksson G, Peterson S, Polanowski $\mathrm{T}$ and Kessler R: Efficacy and tolerability of budesonide/formoterol added to tiotropium in patients with chronic obstructive pulmonary disease. Am J Respir Crit Care Med 180: 741-750, 2009. 